\title{
Torsion of an accessory spleen in an elderly patient
}

\author{
Timothy E.J. Hems and James F. Bellringer \\ The Department of Surgery, The Battle Hospital, Reading, UK.
}

\begin{abstract}
Summary: Torsion of an accessory spleen is recognized as a rare cause of acute abdominal pain in childhood. A case is reported which, however, is unusual in that it occurred in a patient of 75, who had had no previous symptoms which might have suggested the presence of an accessory spleen.
\end{abstract}

\section{Introduction}

We report the case of an elderly patient presenting with an acute abdomen due to torsion of an accessory spleen. Accessory spleens are not an uncommon congenital anomaly. Some cases of torsion of the pedicle resulting in infarction have been described in childhood, but not previously in old age.

\section{Case report}

A 75 year old woman was admitted as an -emergency with a 12-hour history of poorly localized central abdominal pain, vomiting and constipation. On examination, she was in pain but not shocked, with a blood pressure of $155 /$ $80 \mathrm{mmHg}$. There was guarding in the left upper quadrant of the abdomen, but no other abnormality. Abdominal X-ray showed some slightly dilated loops of small bowel in the left upper quadrant. A blood count showed a haemoglobin of $10.4 \mathrm{~g} / \mathrm{dl}$, with no other abnormalities on haematological or biochemical testing. On the basis of these findings, it was decided that she required a laparotomy. After resuscitation with intravenous fluids, she was taken to theatre.

At operation, approximately one litre of old blood was found in the peritoneal cavity. A full laparotomy revealed an accessory spleen on a long pedicle, which had twisted, and was surrounded by haematoma (Figure 1). The pedicle and blood vessels supplying the accessory spleen appeared to arise from the upper border of the pancreas. The spleen itself was macroscopically normal. The splenunculus was resected, peritoneal lavage was

Correspondence: T.E.J. Hems, F.R.C.S. Ed., 9 Cross Street, Oxford, OX4 1BZ, UK

Accepted: 25 April 1990

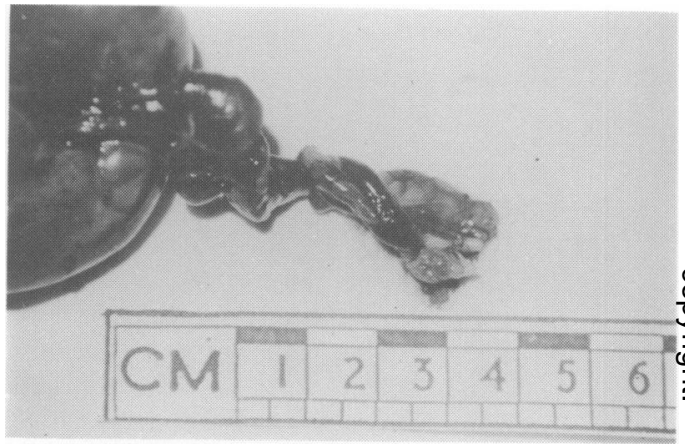

Figure 1 The pedicle of the accessory spleen after removal.

performed, and the abdomen closed. Recovery was uneventful apart from a wound infection.

\section{Discussion}

The incidence of accessory spleens at post-mortem is about $20 \%{ }^{1}$ The commonest position is the splenic hilum, but they are also found related to the tail of the pancreas (as here), the gastrosplenic ligament, and the small bowel mesentery.

There are some reports of torsion of an accessory spleen presenting as an acute abdomen; the majority of these reported cases occurred in childhood. ${ }^{2-5}$ Two cases have also been reported in young adults. ${ }^{6.7}$ Recurrent bouts of abdominal pain, due to intermittent torsion, have also been described ${ }^{8,9}$

A literature search has not, however, revealed any reports of torsion of an accessory spleen in an elderly patient, such as that described above. It 
might be expected that a congenital abnormality would be more likely to present early in life, but this case demonstrates that torsion of an accessory spleen should be considered a possibility at any age.

\section{Acknowledgement}

We should like to thank Mr H. Reece-Smith for permission to report his patient.

\section{References}

1. Blaustein, A. The Spleen. McGraw-Hill New York, 1963, p. 45.

2. Babcock, T.L., Coker, D.D., Haynes, J.L. \& Conklin, H.B. Infarction of an accessory spleen causing an acute abdomen. Am J Surg 1974, 127: 336-337.

3. Settle, E.R. The surgical importance of accessory spleens. Am J Surg 1940, 50: 22.

4. Kitchin, R.J. \& Green, N.A. Torsion of an accessory spleen presenting as acute appendicitis. Br J Surg 1962, 50: 232-233.

5. Mueller, H., Schneider, H., Rueckauer, K. \& Greiner, P. Accessory spleen torsion: clinic, sonographic and differential diagnosis. Klin Padiatr 1988, 200: 419-421.

6. Grunspan, M., Wechler, U. \& Weintraub, S. Torsion of an accessory spleen simulating acute appendicitis. Isr J Med Sci 1981, 17: 458-459.

7. Valleix, D., Grousseau, D., Kalfon, M. \& Descottes, B. Torsion de rate accessoire. Ann Chir 1983, 37: 440-442.

8. Alexander, R.C. \& Romanes, A. Accessory spleen causing attacks of acute abdominal pain. Lancet 1929, ii: 1089-1090.

9. Alexander, R.C. Accessory spleen with recurring torsion of its pedicle. Lancet 1929, ii: 29-30. 